\title{
Construção de Espaço Social Unificado para Formação de Profissionais da Saúde no Contexto do Sistema Único de Saúde
}

\section{Construction of a Unified Social Space for Training Health Care Professionals in the Context of the Single Health System in Brazil}

Maria de Lourdes da Silva Marques Ferreira ${ }^{I}$ Rosângela Minardi Mitre Cotta ${ }^{I l}$ Regina Lugarinho III Marilda Siriani de Oliveira ${ }^{I V}$

\section{KEY-WORDS}

- Single Health System.

- Professional Practice.

- Health Services.
Artigo recebido em: 11/05/2009 Reencaminhado em: 02/09/2009 Aprovado em: 15/10/2009

\footnotetext{
"Universidade Estadual Paulista "Júlio de Mesquita Filho", Botucatu, SP, Brasil.

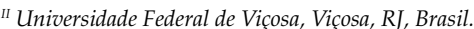

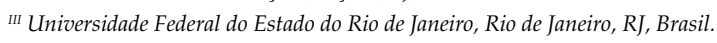

${ }^{\text {IV }}$ Faculdade de Medicina de Marília, Marília, SP, Brasil.
}

The aim of this article was to reflect critically on the importance of the training process for health professionals, focusing on issues involving the production of subjectivity, or healthcare models that approach health education in such a way as to expand individuals' autonomy and their capacity to intervene in their own lives through experience with otherness with users of the production of technical and scientific skills and adequate knowledge of the Single Health System (SUS). The article highlights the relevance of linkage and interaction between health services and educational institutions, problematizing health work, healthcare organization, and teaching, and building socially-oriented meanings and practices through active participation by health sector administrators, faculty, health services users, and students. Finally, the study approaches the importance of constructing social spaces, referred to here as "spaces for possibilities", which tend to define the universe of problems, references, theoretical frameworks, actors, and institutions. This "space of possibilities" allows effectively achieving the desired work relationship in the real world. 


\section{INTRODUÇÃO}

"O homem é uma criação do desejo, não uma criação da necessidade".

Bachelard $^{1}($ Р.36)

Este ensaio pretende refletir criticamente sobre a importância do processo de formação dos profissionais de saúde sob o foco de um ensino que englobe aspectos de produção de subjetividade, como os modelos de atenção que trabalhem uma educação em saúde que amplie a autonomia e a capacidade de intervenção das pessoas sobre suas próprias vidas com a experimentação de alteridade com os usuários, a produção de habilidades técnico-científicas e o adequado conhecimento do Sistema Único de Saúde (SUS).

O processo de reforma do Estado tem sido significativo no País, e as ações desenvolvidas são fundamentais à continuidade e ao avanço do movimento pela Reforma Sanitária, bem como para a concretização do SUS. Por essa razão, o papel indutor do processo de mudança das práticas de saúde, bem como da formação profissional deve ser assumido pelo SUS em suas várias instâncias².

Ressalta-se a relevância da articulação/interação dinâmica entre os serviços de saúde e as instituições formadoras, cabendo ao SUS e às universidades: coletar, sistematizar, analisar e interpretar permanentemente informações da realidade, problematizar o trabalho e as organizações de saúde e de ensino, e construir significados e práticas com orientação social, mediante participação ativa dos gestores setoriais, formadores, usuários e estudantes.

\section{ESPAÇO DE POSSÍVEIS NO CAMPO DA PRODUÇÃO DE SAÚDE}

Todo processo de interação tem por princípio a inclusão de todos os atores relevantes, a forma de construção coletiva, o planejamento de ações direcionadas, a meta-avaliação, a rediscussão e o redirecionamento de ações, a partir de uma discussão e um pensar polissêmicos, com seus muitos e possíveis sentidos convergindo quanto à contraposição ao reducionismo, à fragmentação e à objetivação dos sujeitos ${ }^{3}$.

Na ciência moderna, o homem foi consagrado como sujeito espistêmico e rejeitado como empírico. Nas ciências sociais e por extensão na saúde, a distinção epistemológica entre sujeito e objeto teve de se articular metodologicamente com a distância empírica entre estes mesmos sujeitos e objetos ${ }^{4}$.

Explorar novas possibilidades de representar o conhecimento e criar novos espaços requerem suporte epidemiológico para que se oriente uma nova prática educacional, carac- terizada pelo enriquecimento de ambientes de aprendizagem que privilegiem a atividade do aprendizado em construção compartilhada do conhecimento, valorizando a diversidade e a integração de saberes ${ }^{5}$.

Estamos falando, portanto, da construção de um espaço social unificado que expresse o atendimento de uma formação de profissionais para atuar no SUS, no cumprimento de uma formação acadêmico-científica, ética e humanística para o desempenho técnico e profissional.

Neste sentido, é necessário que se interrogue sobre as condições de possibilidades e os limites de tais espaços. Segundo Bourdieu ${ }^{5}$, os campos de produção de saúde propõem aos que neles estão envolvidos um espaço de possíveis, que tende a orientar sua busca definindo o universo de problemas, de referências, de marcos teóricos, de atores e instituições envolvidos - em síntese, todo um sistema de coordenadas que é preciso ter em mente para entrar no jogo, ressaltando-se que jogar este jogo significa reforçar as próprias condições em que ele é jogado ${ }^{7}$.

Este espaço de possíveis é o que faz com que o tipo de relação de trabalho desejado possa se concretizar no mundo real de forma efetiva. Transcende, portanto, os agentes singulares (docentes, discentes, profissionais de saúde, gestores, população), funcionando como uma espécie de sistema comum de coordenadas que faz com que, mesmo que não se refiram diretamente uns aos outros, esses diferentes atores ainda assim estejam objetivamente situados uns em relação aos outros.

É importante destacar que os espaços institucionais são locais de poder, interesses e projetos de diferentes sujeitos, sendo a análise do poder, portanto, uma análise das relações, porque os sujeitos se relacionam com outros sujeitos segundo suas necessidades e possibilidades. Neste contexto das relações, a enunciação é o produto da interação social ${ }^{8}$. Contribuir para a democratização do conhecimento do processo saúdedoença, da organização dos serviços e da produção social da saúde a partir de um modelo dialógico, estimulando a organização da comunidade para o efetivo exercício do controle social, significa redistribuir poder ${ }^{9}$. Da perspectiva do processo de construção da cidadania e do espírito democrático entre nós, parece ser o momento de fazer avançar esse processo nos espaços micropolíticos, como os espaços dos serviços, contribuindo para que a essência de suas práticas seja a realização da democracia viva em ato ${ }^{10}$.

Neste contexto, os métodos que estabelecem a existência de uma relação inteligível entre as tomadas de posições, ou seja, as escolhas entre os possíveis e as posições no campo da saúde, deveriam apresentar os elementos da prática e teoria necessários em cada caso para a compreensão de como as re- 
lações se estabelecem no cotidiano das diferentes instituições envolvidas. As relações são mediadas pelo diálogo. Este, portanto, demanda um esforço para que algum compartilhamento ocorra, e ele só ocorrerá se seus participantes estiverem motivados a despender tal esforço ${ }^{11}$.

O desenvolvimento da subjetividade necessita da linguagem e do diálogo (intra e interpsicológico) por demandar, do eu e do outro, o reconhecimento mútuo da especificidade das respectivas perspectivas. Na medida em que "eu e outro" nunca conseguem apreender totalmente a perspectiva um do outro, o diálogo sempre, e por excelência, explicitará lacunas entre a experiência singular de cada interlocutor ${ }^{12,13}$.

O diálogo permite, portanto, que o sujeito experimente aquilo que é diverso de sua perspectiva, seja quanto ao conteúdo do que é falado, seja quanto às posições percebidas nas relações interpessoais ${ }^{14}$.

Segundo Limoeiro Cardoso apud Minayo ${ }^{15}$ :

O conhecimento se faz a custo de muitas tentativas e da incidência de muitos feixes de luz, multiplicando os pontos de vista diferentes. A incidência de um único feixe de luz não é suficiente para iluminar um objeto. O resultado desta experiência só pode ser incompleto e imperfeito, dependendo da perspectiva em que a luz é irradiada e da sua intensidade.

A incidência a partir de outros pontos de vista e de outras intensidades luminosas vai dando formas mais definidas ao objeto, vai construindo um objeto que lhe é próprio.

A utilização de outras fontes luminosas poderá formar um objeto inteiramente diverso ou indicar dimensões inteiramente novas do objeto. (p.89)

A prática da construção da cidadania está atrelada às condições da democracia. Assim, considerando ainda a perspectiva dos modos de interação e convívio e a produção do conhecimento, são fundamentais as estratégias de articulação ensino-serviço. A pactuação é uma estratégia que deve ser sempre clara e bem definida, e que articule os diferentes atores de forma democrática e plural. Fazer o possível avançando proativamente significa aceitar que nem todos estão no mesmo nível de conhecimento, entendimento, necessidade e/ou desejo.

Os atores sociais, quer se trate de indivíduos, quer de grupo, convivem na e pela diferença. Estes atores ocupam posições relativas em um espaço de relações que, ainda que invisível e sempre difícil de expressar empiricamente, é uma realidade mais real e um princípio real dos comportamentos e dos indivíduos e dos grupos ${ }^{6}$.
Construir e descobrir o princípio da diferenciação que permite reengendrar teoricamente o espaço no campo da saúde coletiva, empiricamente observada, possibilita entender a estrutura da distribuição de poder ou dos tipos de arranjos nas relações existentes no universo sanitário e que variam de acordo com os lugares e com os momentos, ou seja, com o tempo e o espaço.

O espaço sanitário e institucional pode ser entendido como um campo de forças cuja necessidade se impõe aos agentes sociais que neles se encontram envolvidos, e como um campo de lutas, no interior das quais estes agentes se enfrentam, com meios e fins diferenciados conforme sua posição na estrutura do campo de forças, contribuindo para conservar ou transformar sua estrutura. Algo assim, como um grupo mobilizado para e pela defesa de seus interesses, não pode existir senão ao preço e ao termo de um trabalho coletivo de construção inseparavelmente teórico, reflexivo, mas, também, prático, participativo $^{6}$. O campo da visibilidade do professor é o que o referencia, seu chão firme e o espaço teórico-prático. Para ocorrerem reflexões e transformações, esse campo precisa ser percebido como espaço próprio que é modificado quando tem sentido. "Todo ato educativo tem uma intencionalidade de formação"16 (p.34)

Contudo, é necessário um trabalho de constituição ou de consagração para criar um grupo unido e coeso em favor de uma atenção centrada no usuário, que contemple o acolhimento à demanda e busca ativa com avaliação de vulnerabilidade. A clínica ampliada e a saúde coletiva referenciada na rede de atenção básica terão tanto mais oportunidades de serem bemsucedidas quanto mais os atores sociais sobre os quais elas atuam estejam incluídos a se reconhecerem mutuamente e a se reconhecerem em um mesmo projeto político-sanitário ${ }^{3,6}$.

Mas construir vínculos duradouros inter e entre os espaços acadêmicos e as instituições de saúde depende tanto do desenho organizacional com base na lógica da relação multi e interprofissional, como também da ligação longitudinal, horizontal, ao longo do tempo entre docentes, discentes, equipes de saúde e usuários ${ }^{17}$.

\section{NECESSIDADE DE TRANSFORMAÇÃO DA PRÁXIS PROFISSIONAL NO CONTEXTO DA SAÚDE}

As transformações das práticas sanitárias passam pela emergência e valorização de novos saberes, por uma postura mais dialógica da equipe entre si e com os usuários, por uma abertura conceitual e científica em relação ao modelo da biomedicina e maior responsabilidade política e ideológica dos gestores ${ }^{18}$.

Essas transformações são potenciais construtores de vínculo, aproximando quem oferece ou presta serviço de quem o 
recebe, e personalizando a relação, que deve ser compromissada e solidária, e aparecer como fruto de uma construção social e parte de um esforço que envolve a equipe, as instituições e a comunidade ${ }^{19}$

A superação do monopólio do diagnóstico de necessidades e de se integrar à voz do outro é mais que a construção de vínculos/responsabilização. É uma efetiva mudança na relação de poder técnico-usuário, evidenciando as possibilidades que tem o ser social de passar do reino da necessidade para o reino da liberdade ${ }^{20}$.

Para o andamento desse processo, é preciso haver uma interação entre os profissionais das instituições de ensino, das instituições de serviço e da comunidade, em busca de sintonia entre os diferentes saberes produzidos. A prática do processo ensino-aprendizagem é um espaço de confronto entre os conhecimentos teóricos propiciados pelo curso de formação e as ideias próprias de cada aluno, sobre o que é aprendido e experienciado no espaço escolar ${ }^{21}$. Assim, a intersubjetividade e a abordagem teórica se articulam dialeticamente, aproximando o espaço de possíveis com o espaço de construção de saúde.

Neste sentido, usar como recurso metodológico a construção ativa de espaços coletivos, arranjos ou dispositivos que propiciem a interação entre os sujeitos, incluindo metodologias dialéticas que tragam ofertas externas e que ao mesmo tempo valorizem as demandas do grupo, pode facilitar a construção deste espaço unificado ${ }^{17,22}$.

\footnotetext{
Nessa construção, a hegemonia é um processo de articulação de diferentes interesses para se construir uma vontade coletiva, sendo um processo de formação de sujeitos no qual a capacidade de transcender interesses corporativos e particulares, de fazer compromissos e negociar são características fundamentais nessa construção em processo, uma articulação sempre submetida à reelaboração e renovação como ação política na direção da transformação $\operatorname{social}^{23} \cdot(p .73)$
}

Aparentemente, os profissionais de saúde resistem a se aproximar de cenários que consideram distantes da idealização de práticas de saúde ${ }^{24}$. O SUS tem assumido papel ativo na reorientação das estratégias e modos de cuidar, tratar e acompanhar a saúde individual e coletiva, com importantes repercussões nas estratégias e modos de ensinar e aprender. No processo de ensino-aprendizagem, é preciso responder a questão: formados para atuar onde? Neste sentido, um olhar crítico e inovador revela a necessidade de re-formar os profissionais para atuarem no SUS ${ }^{2}$.
A este ideal correspondem, como cenário ideal de práticas, o hospital e outros equipamentos que permitam acesso às tecnologias. Há falta de recursos humanos na rede pública de atendimento à saúde, muitas vezes, pela falta de comprometimento dos profissionais com a população e seus problemas. É preciso considerar o princípio da universalidade do SUS.

Essa visão do que seja o ideal de prática para atuação do profissional universitário tem influenciado a formação acadêmica de futuros profissionais. Logo, esses profissionais serão responsáveis pelo processo de formação acadêmica nas instituições de ensino, cabendo a eles eleger o campo de prática dos acadêmicos.

Neste sentido, para mudar o processo de formação de graduação, seria necessário enfrentar, nas escolas, essas contradições da categoria médica. Construir uma nova postura ética e um novo ideal profissional, e transformar a prática dos profissionais envolvidos com a educação dos estudantes são parte dessa tarefa ${ }^{24}$.

O local de aprendizagem de prática para o estudante deve realmente extrapolar o recurso da prática para se transformar em cenário de formação. Para isso, o profissional do serviço deve atuar como participante do processo de aprendizagem.

Embora a parceria academia-serviço seja historicamente utilizada na realização de estágios em todas as carreiras da área de saúde, geralmente os profissionais dos serviços ficam responsáveis pela supervisão do desempenho dos estudantes, e os docentes pela teorização e supervisão geral do estágio. Numa proposta de currículo orientado por competência, o trabalho de apoio e de facilitação do desenvolvimento de capacidades dos estudantes em situações reais ocorre em ação e, por isso, a prática educacional ganha novo sentido. Dessa forma, docentes e profissionais dos serviços necessitam construir e/ ou ressignificar suas próprias capacidades tanto na área educacional como na área de cuidado à saúde de cidadãos e comunidades.

A relação educacional num projeto de construção e ressignificação de saberes requer maior horizontalização, ação cooperativa, humanizada, solidária e ética, postura ativa, crítica e reflexiva, desenvolvimento da capacidade de aprender a aprender, identificação dos próprios valores e abertura para a superação de limites e constrições. A avaliação ocupa um espaço estratégico, tanto no desenvolvimento e melhoria do processo de ensino-aprendizagem, como na própria gestão curricular ${ }^{25}$.

A participação de atores externos à universidade é uma realidade importante para a construção de parcerias. Nessa parceria deve haver uma sincronia entre o que a universidade e o serviço querem e precisam. Feuerwerker e Sena ${ }^{24}$ consi- 
dera indispensável estabelecer mecanismos de cogestão do processo de ensino-aprendizagem e de produção da saúde entre universidade, serviços de saúde e comunidades. A integração docente assistencial propicia um processo de trabalho conjunto, que leva em conta os interesses, necessidades e potencialidades dos outros parceiros. Para isso, é interessante criar espaços reais de troca, interlocução e transformação mútua por meio da horizontalização. Os parceiros têm interesses distintos, sendo importante reconhecer essa heterogeneidade e utilizar estratégias para aprender a trabalhar com ela.

No contexto da formação de profissionais de saúde, a abordagem dialógica de competência possibilita a reflexão sobre as práticas profissionais e uma construção dialogada entre os mundos da escola e do trabalho com a sociedade, a partir da explicitação de diferentes interesses, valores e saberes, sociais e historicamente constituídos ${ }^{25}$. Neste contexto, a ênfase é no modelo dialógico da educação. O velho modelo hegemônico, em sua essência divergente dos princípios e dimensões da integralidade, do cuidado em saúde, do acolhimento, da humanização e solidariedade, tão necessários para uma prática baseada na alteridade e espiritualidade do cuidado em saúde, cede gradativamente espaço para esta nova forma dialógica de se pensar a saúde ${ }^{3,26}$.

\section{REFERÊNCIAS}

1. Bachelard G. A psicanálise do fogo. Trad. Maria Isabel Braga. Lisboa: Estúdios Cor; 1938.

2. Ceccim RB, Feurwerker LCM. O quadrilátero da formação para a área da saúde: ensino, gestão, atenção e controle social. Physis. 2004;14(1):41-65.

3. Alves VS. Um modelo de educação em saúde para o Programa de saúde da Família: pela integralidade da atenção e reorientação do modelo assistencial. Interface Comun. Saúde Educ. 2005; 9(16):39-52.

4. Santos BS. Um discurso sobre as ciências. São Paulo: Cortez; 2004.

5. Nevado RA. Espaços Interativos de Construção de Possíveis: uma nova modalidade de formação de professores. Porto Alegre; 2001. Doutorado [Tese] — Universidade Federal do Rio Grande do Sul.

6. Bourdieu P. Espaço social e campo do poder. 6a. ed. São Paulo: Papirus; 2005.

7. O`Donnell G. Sobre o estado, a democratização e alguns problemas conceituais: uma visão latino-americana com uma rápida olhada em alguns países pós-comunistas. Novos Estudos. 1993;36:123-45.

8. Bakhtin MM. Marxismo e filosofia da linguagem. São Paulo: Hucitec; 1986.
9. Brasil. Ministério da Saúde. Saúde da Família: uma estratégia para a reorientação do modelo assistencial. Brasília (DF); 1997.

10. Teixeira RR. O acolhimento em um serviço de saúde entendido como uma rede de conversações. In: Pinheiro R, Mattos R, orgs. A construção da integralidade: cotidiano, saberes e práticas em saúde. Rio de Janeiro: IMS-UERJ; 2003. p.89-112.

11. Guimarães DS, Simão LM. Intersubjetividade e desejo nas relações sociais: o caso dos jogos de representação de papéis. Interacções. [periódico na Internet]. 2007 [acesso em 8 ago. 2007];7:30-54. Disponível em: http:/ /www.eses.pt/ interaccoes.

12. Crossley N. Intersubjectivity: the fabric of social becoming. Londres: Sage publications; 1996.

13. Simão LM Beside rupture - disquiet; beyond the other alterity. Culture Psychology. 2003;9(4): 449-59.

14. Simão LM. Alteridade no diálogo e construção de conhecimento. In: Simão LM, Martínez AM, eds. O outro no desenvolvimento humano. São Paulo: Casa do psicólogo; 2004.

15. Minayo MCS. O desafio do conhecimento: pesquisa qualitativa em saúde. São Paulo: Hucitec; 1993.

16. Hernandez F. A construção da subjetividade docente como base para uma proposta de formação inicial de professores de artes visuais. Santa Maria: UFSM; 2005.

17. Campus WSG. Um método para análise e co-gestão de coletivos. 2a ed. São Paulo: Hucitec; 2005.

18. Favoreto CAO, Camargo Junior KR. Alguns desafios conceituais e técnico operacionais para o desenvolvimento do Programa de Saúde da Família como uma proposta transformadora do modelo assistencial. Physis. 2002;12(1):59-76.

19. Silva RVB, Stelet BP, Pinheiro R, Guizardi FL. Do elo do laço: o agente comunitário na construção da integralidade em saúde. In: Pinheiro R, Mattos RA, orgs. Cuidado: as fronteiras da integralidade. Rio de Janeiro: IMS-UERJ; São Paulo: Hucitec; 2004. p. 75-90.

20. Simionatto I. O social e o político no pensamento de Gramsci. In: Aggio A, org. Gramsci: a vitalidade de um pensamento. São Paulo: Ed. Unesp; 1998. p.37-64.

21. Vasconcellos ST. Estágio, formação e docência em arte: as marcas presentes nos relatos de um grupo de alunos. R. Cient /FAP. 2008;3:99-110.

22. Campus WSG. Saúde Paidéia. São Paulo: Hucitec; 2003.

23. Dagnino E. Cultura, cidadania e democracia. A transformação dos discursos e práticas esquerda latino-americana. In: Alvarez S, Dagnino E, Escobar A, orgs. Cultura e política nos movimentos sociais latino-americanos. Belo Horizonte: Novas Leituras; 2000. p. 61-102. 
24. Feuerwerker LCM., Sena RR. Contribuição ao movimento de mudança na formação profissional em saúde: uma avaliação da experiência UNI. Interface Comun.Saúde Educ. 2002;6(10):37-50.

25. Lima VV. Competência: distintas abordagens e implicações na formação de profissionais de saúde. Interface Comun.Saúde Educ. 2005;9(17):369-79.

26. Ayres JRCM. O cuidado, os modos de Ser (do) humano e as práticas de saúde. Saúde Soc. 2004; 13(3):16-29.

\section{CONTRIBUIÇÃO DOS AUTORES}

O artigo foi construído por todos os autores nas seguintes etapas: elaboração do projeto, levantamento bibliográfico, escrita do ensaio, análise e revisão da versão final.

\section{CONFLITO DE INTERESSES}

Declarou não haver

\section{ENDEREÇO PARA CORRESPONDÊNCIA}

Maria de Lourdes da Silva Marques Ferreira

Departamento de Enfermagem - Faculdade de Medicina de Botucatu - Unesp

Rubião Júnior, $\mathrm{S} / \mathrm{N}$

Campus Universitário - Botucatu

CEP 18618-000 - SP

E-mail:malusa@fmb.unesp.br 